\title{
Reason for Non-Evaluation ICSR Terminology
}

National Cancer Institute

\section{Source}

National Cancer Institute. Reason for Non-Evaluation ICSR Terminology. NCI Thesaurus.

Code C54593.

Terminology used in Individual Case Safety Reports to specify a reason for non-

evaluation of a problematic medical product, section F3.3 of FDA MedWatch Form. 